\title{
Is There A Wireless Community Informatics?
}

\author{
Michael Gurstein, Ph.D. \\ Editor in chief $<\underline{\text { editor@ci-journal.net }}>$
}

In some earlier writing ${ }^{1}$ I asked the question whether there could be a wireless community informatics and whether we can in fact treat wireless "communities" as communities in the same way as we understand other communities from a CI perspective.

The papers in this issue I think, give a resoundingly positive answer to the first question but still leave open to research and practice the second; that is, does the availability and use of wireless connectivity enhance community and can it be used as a means for building communities? I say that there can be a wireless community informatics based on the work in this issue because what can see here is the way in which wireless connectivity can become an enhancement or an extension or even an alternative to other forms of connectivity and in this way become the basis for extending access (and thus use) to previously excluded populations.

The second question though is in some sense more intriguing. What effect does wireless connectivity and the fluidity and mobility of access-enhanced movement have on the capacity to build trusting relationships, to achieve consensus around values, to collaborate towards the realization of collective goals? The image, or perhaps better, the metaphor of wirelessness is of the "nomad", the individual who moves from place to place carrying his "locality" with him (or her or even as a family). The "nomad" in this sense is a-local, having little connection to the space that she occupies and no real on-going connection to others occupying the same spatial geography. This does not on its face appear promising for the building of community.

The question of the relationship between wireless and community building is in fact a very serious one from a community informatics perspective as it immediately presents the challenge of whether there can be for example an "urban" community informatics. The primary models and examples for locationally based CI are drawn for the most part from the rural, the small town, or relatively stable on-going urban ethnic enclaves. It is in these settings that "community" is easiest to discern and where, as follows, the relationship between ICTs and community enabling has the most evident applicability. Here the link between community and geography is a direct and visible one and extending that linkage to include ICTs is natural and congruent with other elements of community life.

This is not the case in urban environments where there is a much higher degree of specialization, segmentation, and a de-linking of the physical from the social. In complex modern urban environments community needs to be built and continuously recreated as the patterns of interaction almost inevitably are casual, fragmented and transitory. Whether wireless connectivity simply accelerates these processes or can provide a means to challenge them and to allow for the

1 Gurstein, Michael (2007) What is Community Informatics (and Why Does It Matter)? POLIMETRICA, Milan http://eprints.rclis.org/archive/00012372/01/WHAT IS COMMUNITY INFORMATICS reading.pdf Some of the above text is taken from this publication. 
intensification of interaction from which community can be built is still an open question. On the face of it however, a technology which is built on the metaphor of the "nomad" would not immediately suggest itself for this purpose.

The question remains, whether there is a wireless community informatics beyond that of facilitating access. Perhaps, the broader concept of a wireless CI is nothing more than a peculiar artifact arising from the circumstance that many of the early wireless innovators, while having somewhat parallel backgrounds to the early community networking innovators (progressive politics, university education, technical proficiency, youthful) often referred to themselves as "community networkers" even though they evidently had little knowledge of (or interest in) more traditional or long standing community networking advocates or institutions.

A further difficulty with thinking about a "wireless community informatics" is that wireless as an infrastructure is necessarily virtual and placeless thus immediately making the creation of community connections (the normative integration necessary for community formation) exceedingly difficult. Wireless users are simply those who use a wireless connection to obtain Internet access and need have no other links or connections to other users either on the Internet or through the same Internet Service Provider (ISP). However, as some have identified, the fact that a wireless connection does have some degree of geographical anchoring (individuals gain access through some sort of geographically anchored "hotspot") opens up the possibility of creating a degree of interconnection among users over and above that of a random and anonymous (to each other) group of users of a single ISP.

Ile Sans Fils in Montreal use this limited amount of interaction as a way of interposing information as a basis for local promotion and development. Whether this can lead to enhancement of community interaction is still I believe an open question.

But as the world becomes increasingly urban and wireless the need (and opportunity) for the use of this form of untethered access not only to enhance mobility, fluidity and transience but also possibly as a means for facilitating interaction and thus perhaps interconnection as a basis for a re-formation of community (or perhaps a re or updating of the definition of community) immediately presents itself.

On a different, but unfortunately very sad note: this issue includes a brief appreciation of Steve Cisler, a pioneer in the field of Community Informatics, a leader in the library applications of information technologies and a longstanding friend of this journal. Steve passed away recently, and we along with others in our small community are remembering him and celebrating his life and work including in this issue through a personal appreciation by Associate Editor Eduardo Villanueva.

My personal thanks to Alison Powell and Sascha Meinrath for their excellent work in bringing this most timely content rich special issue to fruition and through this issue raising within the CI community some very important and intriguing questions about the very nature of Community Informatics itself. 